
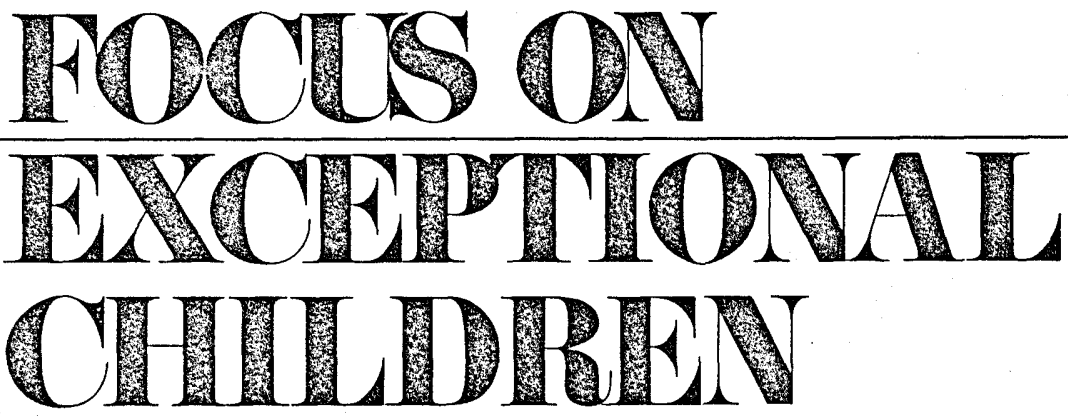

\title{
The Efficacy of Special Education Interventions and Practices: A Compendium of Meta-Analysis Findings
}

\author{
Kenneth A. Kavale and Gene V Glass
}

Special education, by definition and in practice, serves an exceptional clientele, provides curricula, utilizes unique materials, and employs distinct methods and techniques for teaching. Although these characteristics set it apart, they also raise the question of how effective are the unique procedures used in special education. Milofsky (1974) suggested that, despite the growth in special education over the last quarter century, the results have been less than special. The question: Is special education special?

As a discipline, special education has produced a voluminous and variegated data base. The findings from individual studies have proved to be conflicting, variable, and sometimes paradoxical. Special education research, like other domains of inquiry, produces fragile findings. This should not be interpreted, however, to imply that special education research is either inconsequential or devoid of meaning and inspiration (Cruickshank, 1978). In fact, Light (1979) suggested that agreement in results may not always be the sought after goal, and variation in research findings should not be vilified but, rather, explicated for the possibility of finding important information.

The findings from individual studies are best harnessed by systematic synthesis, not by proliferation of primary research. Knowledge must be cumulative, and if accumulated results can provide general and accurate conclusions, policy makers in special education will be in a position to implement decisions with confidence.

\section{METHODS OF RESEARCH SYNTHESIS}

In the past, research synthesis was shaped by the size of the research literature. For example, the question of the efficacy of special versus regular class placement

Kenneth Kavale is an Associate Professor of Education at the University of California, Riverside. Gene Glass is a Professor of Education and a Professor of Psychology, School of Education, University of Colorado at Boulder, and a Research Professor of Psychiatry, Health Sciences Center, Boulder.

๑) Love Publishing Company, 1982 
was probably satisfactorily answered by a narrative, rhetorical integration during the 1940s (Shattuck, 1946), but the burgeoning literature became increasingly difficult to harness (Dunn, 1968; Johnson, 1962; Kirk, 1964; Guskin \& Spicker, 1968; Blatt \& Garfunkel, 1973). An unwieldy literature generates methods of integration that are unsystematic and fall short of meeting rigorous scientific standards. The standards of objectivity, verifiability, and replicability are often overlooked in an effort to gain a rational conclusion.

The most common method of research integration is the narrative review whose purpose is to reach an overall conclusion by a verbal report of individual studies. Complications arise, however, when individual study findings do not agree, since the review process is based upon inference. What is the proper inference when findings are not in agreement? Typically, conclusions are qualified either by criticizing the research design of an individual study or by discounting the findings of a study that did not fit some stipulative parameters for sampling, measurement, or analysis. Such qualifications, although eliminating conflicting results, are subjective and, as such, inject the possibility of bias and prejudice. The literature base is reduced and the remaining studies reveal a consistency, but this consonance was achieved for the wrong reasons (Glass, McGaw \& Smith, 1981).

FOCUS ON EXCEPTIONAL CHILDREN (ISSN 0015-5IIX) (USPS 203-360) is published monthly except June, July, and August as a service to teachers, special educators, curriculum specialists, administrators, and those concerned with the special education of exceptional children. This journal is abstracted and indexed in Exceptional Child Education Resources, and is also available in microform from Xerox University Microfilms, Ann Arbor, Michigan. Subscription rates, $\$ 15.00$ per year. Copyright 1982, Love Publishing Company. All rights reserved. Reproduction in whole or part without written permission is prohibited. Printed in the United States of America. Second class postage is paid at Denver, Colorado. POSTMASTER: Send address changes to:

\footnotetext{
Love Publishing Company

Executive and Editorial Office

1777 South Bellaire Street

Denver, Colorado 80222

Telephone (303) 757-2579
}

\section{EDITORIAL BOARD}

Edward L. Meyen

University of Kansas

Richard J. Whelan

University of Kansas Medical Center

$\begin{array}{cc}\text { Carolyn Acheson } & \text { Stanley F. Love } \\ \text { Senior Editor } & \text { Publisher }\end{array}$

The inability of chronologically arranged verbal descriptions to portray the accumulated knowledge led to methods based upon classifications and measurements of the conditions and results of studies. Typically, studies were classified in contingency tables with respect to the significance or nonsignificance of the test of a statistical hypothesis. This "box-score" integration is based upon a "voting method" (Light \& Smith, 1971) wherein the number of studies falling into each category is tallied and the category containing the plurality of studies is declared the "winner." The winning category is used as the basis for conclusions about the topic studied.

One primary difficulty with box-score integrations is the disregard of sample size. Since large samples produce more statistically significant findings than do small samples, the box-score method is biased against studies with small samples. For example, suppose in a pool of 10 studies that nine with small sample sizes are in the expected direction but fail to reach statistical significance, while one study with a large sample is significant. The box-score tally is one for and nine against, which is a conclusion at variance with one's best instincts.

A second difficulty of the box-score method is the discarding of good descriptive information. Is anything known if 40 of 50 studies reveal mainstreaming to be more efficacious than segregation for exceptional children? The real question is the magnitude of the experimental relationship: Does mainstreaming win by a nose or in a walk-away? Tallies of statistical significance or nonsignificance reveal little about either the strength or importance of a relationship. Unfortunately, tests of statistical significance are strongly believed to be more informative than they actually are. The mathematical properties of the box-score method of integration were evaluated by Hedges and Olkin (1980), and their findings cast the method in a most unfavorable light. Clearly, research synthesis by means of box-score methods is not entirely acceptable.

\section{TRADITIONAL REVIEW TECHNIQUES: THE PROBLEM}

The failure of common methods of research synthesis to provide reliable conclusions undermines confidence in a discipline such as special education. The usual conclusion of a research review is that the research is in poor shape and should be improved by better designs, better measures, and better analyses. Take, for example, the longstanding debate surrounding the effectiveness of psycholinguistic training. The ITPA has served as the 
clinical model for a variety of remedial and developmental language programs. These programs are based upon the assumption that language behavior is composed of discrete components that can be remediated. This assumption precipitated a continuing debate over the efficacy of psycholinguistic training using the ITPA as the criterion measure.

After some five years of feckless debate, polemics abounded but the nagging question remained: What is really known about the efficacy of psycholinguistic training? The obfuscation caused by narrative and voting methods of research integration clouds the primary issue. Debate focuses not upon the principal issue but, rather, becomes entangled in a maze of detail only tangentially related to the major question. Under these circumstances, reviewers are bound to see things differently. Yet, research integration should not be subject to the whims and idiosyncracies of individual reviewers. The tenets of scientific inquiry are too often forgotten in a context in which the task is to synthesize a number of empirical studies instead of performing a single primary study (Glass et al., 1981).

It is not important that Hammill and Larsen (1974, 1978), Minsk off (1975), and Lund, Foster, and McCallPerez (1978) disagreed but, rather, that they did not approach the synthesis of research with a methodology so explicit, unambiguous, and well defined that anyone with even a cursory knowledge of special education could examine the same evidence and reach the same conclusion. What is required is an attitude of research synthesis that resembles techniques for collecting and analyzing primary data.

\section{STATISTICAL TECHNIQUES OF RESEARCH SYNTHESIS}

Toward this end, Glass $(1976,1977)$ and Glass et al. (1981) proposed meta-analysis, the analysis of analyses, as a means for statistically integrating a body of literature. As a statistical analysis of the findings of many empirical studies, meta-analysis satisfies the following basic requirements: (1) it is quantitative - uses statistical methods for organizing and extracting information from large data bases, (2) it eliminates bias in study selection by not prejudging research quality, (3) it makes use of all information - study findings are transformed to commensurable expressions of magnitude of experimental effect, (4) it detects statistical interactions study characteristics that mediate findings are defined, measured, and their covariation with findings studied, and (5) it seeks general conclusions - the demand for policy implications requires practical simplicity that does not do violence to more interactive conclusions.

\section{THE TECHNIQUE OF META-ANALYSIS}

The activities normally included in "primary" research are equally applicable to meta-analysis and include: problem formulation, sample selection, data classification, and data analysis.

\section{Formulating Problems}

For many areas of special education, one can locate unanswered questions from available theory, examination of prior research, or intuition, insight, and ingenuity (Jackson, 1980). In an effort to capture the texture of an entire domain, the initial questions in meta-analysis are typically broad in scope. For example: "Is special class placement effacacious for exceptional children?" or "Is psycholinguistic training effective?"

\section{Population and Sample}

Any research synthesis is affected by the population of primary studies reviewed. Representativeness of an entire domain is best assured by locating as many of the existing studies as possible. But no matter how ambitious the efforts to find all empirical research in a domain, the effort is likely to be frustrated because of the proliferation of literature in too many places. Fortunately, Rosenthal (1979) addressed the "file drawer problem" - the possibility that journals are filled with only the $5 \%$ of studies that show Type I errors, while office file drawers are filled with the $95 \%$ of studies with nonsignificant findings - and showed that many hundreds of unpublished manuscripts would have to exist unpublished for findings based on a few dozen studies to average zero.

With study collection complete, attention is focused upon the definition and coding of study features, characteristics that are assumed to have a functional relationship with the phenomenon being studied. These characteristics can be roughly classified as either substantive or methodological. Substantive features are characteristics specific to the problem under study. Methodological characteristics are more general and include design considerations. 
The purpose of describing both substantive and methodological features is the same: to determine whether the findings differ depending on certain of the characteristics of the studies. Meta-analysis seeks a comprehensive statistical description of not only the findings in general but also a description of how the findings vary with respect to both substantive and methodological characteristics.

\section{Data Analysis}

With substantive and methodological features described, attention is directed to the statistical accumulation of the findings from separate studies into a review summary. This is accomplished, in the case of experiments, with a statistic that represents the magnitude of experimental effect transformed to a common scale. The magnitude of experimental effect, or "effect size" (ES), is defined by

$$
\mathrm{ES}=\frac{\overline{\mathrm{X}}_{\mathrm{e}}-\overline{\mathrm{X}}_{\mathrm{c}}}{\mathrm{S}_{\mathrm{c}}}
$$

where $\bar{X}_{e}=$ average score for experimental group on outcome measure, $X_{C}=$ average score for control group on outcome measure, and $\mathrm{S}_{\mathrm{C}}=$ standard deviation of the control group.

The calculated ES describes the experimental effect in standard deviation units. Individual study findings are thus transformed into a common metric. Because ES represents a standard mean difference, comparisons based upon different outcome measures are rendered comparable, even though their conceptual comparability is not so easily dealt with. Although a portion of any collection of studies is likely to reveal the absence of the fundamental statistics required for ES calculation, Glass et al. (1981) derived statistical procedures for reconstructing $\underline{E S}$ 's by solution of equations from $\underline{t}$ or $\underline{F}$ ratios, nonparametric inferential tests, or percentages (probit analysis).

\section{The Meaning of Effect Size}

Interpretation of ES is comparable to a z-score if the reasonable and unobjectionable assumption of a normal distribution of outcomes is made. The meaning of ES can then be translated into notions of overlapping distributions and comparable percentiles. For example, suppose a hypothetical study investigating the efficacy of Temporal Centripetal Therapy revealed an ES of +1.00 . This would indicate that a subject at the 50th percentile of the control group would be expected to rise to the 84th percentile of the control group after therapy.

The obtained ES of +1.00 indicates a superiority of one standard deviation for the treatment group. If two separate distributions are drawn for those receiving therapy and those in the control condition, the distributions will be separated by one standard deviation at their means, as shown in Figure 1.

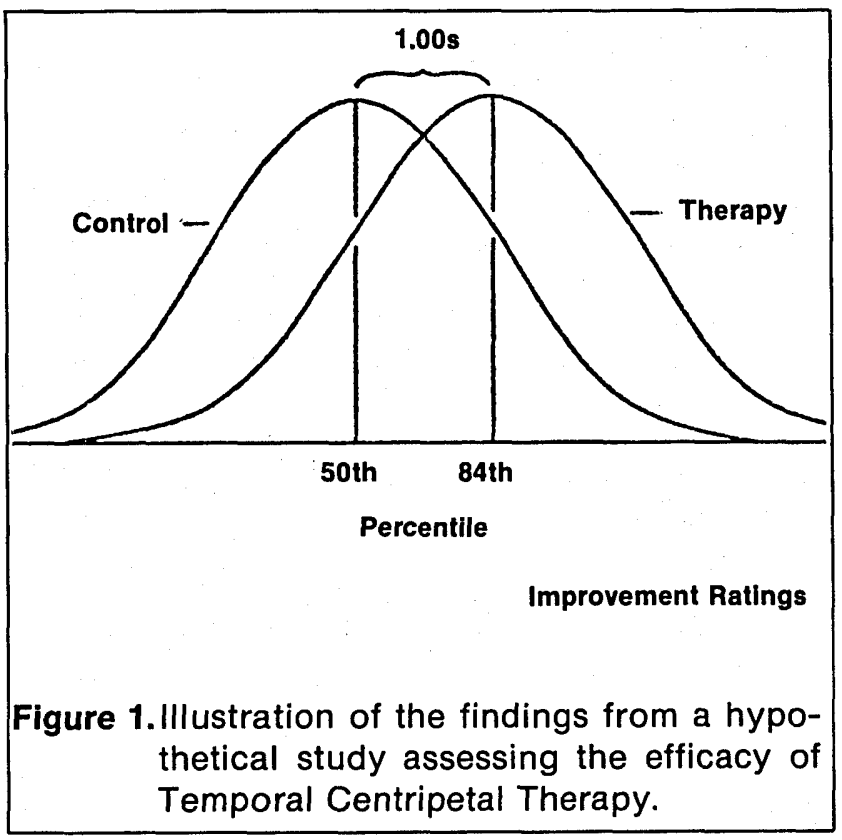

The average of the therapy curve is located above $84 \%$ of the area under the control group curve. This relationship suggests that the average child receiving therapy was better off than $84 \%$ of the control group, while only $16 \%$ of the control group was better off at the end than the average child receiving therapy.

Such interpretations are readily comprehended; in some instances ES's are meaningful without comparison. For example, a zero ES or negative ES is categorically clear and meaningful in and of itself. Adding meaning to ES by reference to known interventions is also possible. For example, it is known that the average third-grade pupil will score 3.0 in early September and 4.0 at the end of the school year on an achievement measure. With a standard deviation of 1.0 grade-equivalent units on many elementary achievement tests, the ES for one year's instruction at the elementary school level is +1.00 . 
Finally, ES's can be interpreted with respect to the accumulated findings of other meta-analyses. For example, psychotherapy for about 20 hours produces an $\overline{\mathrm{ES}}$ (average effect size) of .68 (Smith \& Glass, 1977), open classrooms produce an ES of -.12 when compared to traditional classrooms (Peterson, 1980), drug therapy produces an $\overline{\mathrm{ES}}$ of .70 for adult psychological disorders (Miller, 1980), and reducing class size from 25 to 5 students increases achievement with an $\overline{\mathrm{ES}}$ of .41 (Glass \& Smith, 1979) while reduced class size produces an $\overline{\mathrm{ES}}$ of .49 on affective outcomes (Smith \& Glass, 1980), among others. Using such accumulated findings as points of reference, particular ES's will gain meaning by reference to what is typical in similar circumstances.

Thus, interpretation of ES should not be made in a vacuum; it requires a context to provide meaning. An ES of 3.5 or .1 possesses no inherent value when dissociated from a context of decision and comparative value. Depending upon circumstances, an ES of 2.00 may be "poor" while an ES of .2 may be "good." No sensible $a$ priori judgment based upon the association of ES regions with descriptive adjectives such as "small," "medium," "large," and the like is possible. Rather, judgment of the value of an ES must be based upon the total circumstances surrounding the ES which is likely to vary from setting to setting.

\section{META-ANALYSIS AND SPECIAL EDUCATION}

The approach to research synthesis offered by metaanalysis has been criticized on the grounds that it "mixes apples and oranges" - uncommensurable studies are forced together to produce a suspect conclusion. Different studies, however, are the very ones that require integration to find the knowledge that lies untapped in the extant research. Special educators have too long been in the mildly embarrassing position of knowing less than has been proven.

The need for meta-analysis in special education is clear. To meet this need, several meta-analyses have been undertaken to investigate interventions and practices in special education.

\section{Special Versus Regular Class Placement}

Passage of Public Law 94-142 mandated placement in the "least restrictive environment" which, for many exceptional children, meant placement in the regular class. Justification was found in efficacy studies suggesting that the special class may be inappropriate for the education of exceptional children (Dunn, 1968; Johnson, 1962; Kirk, 1964). The research literature, however, has been criticized for a number of methodological flaws that confound unilateral interpretation (Guskin \& Spicker, 1968; MacMillan, 1971). Consequently, research has provided little convincing evidence that either supports or rejects the efficacy of special or regular class placement for exceptional children.

Carlberg and Kavale (1980) performed a meta-anaysis on 50 studies examining the "efficacy" question. The studies included experiments comparing special class students with those who might otherwise have been placed in special classes but for experimental purposes were placed in regular classes. It was not a comparison of exceptional versus average pupils. In this case, the special class was treated as the experimental group, which means a positive ES favors the special class while a negative ES favors the regular class.

The 50 studies produced 322 ES measurements and, at the highest level of aggregation, yielded an $\overline{\mathrm{ES}}$ of -.12 . These data represented approximately 27,000 students, who averaged 11 years of age, with a mean IQ of 74 , and who remained in the special class for a little under two years. Approximately $58 \%$ of the ES's were negative: in more than half the cases, special classes were less effective. Since the average comparison regular class subject would be at the 50th percentile, the effects of approximately two years of special class placement were to reduce the relative standing of the average special class pupil by 5 percentile ranks.

Efficacy studies generally measured two outcomes: achievement and social/personality variables, which revealed ES's of -.15 and -.11 , respectively. Thus, special class placement was inferior to regular class placement regardless of outcome measure.

These findings lend support for a significant, albeit small, negative effect for special class placement. The critics were apparently correct; special class placement produced no tangible benefits. The ES measurements were classified and averaged in a number of different ways. They were correlated with important study features, but the primary finding was not challenged. Regardless of age, IQ, length of special class placement, and the like, the fact remained: the special class was an inferior placement option.

This meta-analysis brought to light, however, a surprising finding related to diagnosis of pupils. The findings are shown in Table 1. Special class placement was most disadvantageous for exceptional children whose primary problem was lowered IQ levels. The average learning disabled (LD) or behaviorally/emotionally disturbed $(\mathrm{BD} / \mathrm{ED})$ pupil in a special class was better off 
TABLE 1

Average Effect Size by Special Education Diagnosis

\begin{tabular}{lcr}
\multicolumn{1}{c}{ Dlagnosis } & $\begin{array}{c}\text { Average Effect of } \\
\text { Speclal vs. Regular } \\
\text { Placement }\end{array}$ & $\begin{array}{r}\text { No. of } \\
\text { Effect } \\
\text { Slzes }\end{array}$ \\
\hline $\begin{array}{l}\text { Educable Mentally Retarded } \\
\text { (EMR) (IQ 50-75) }\end{array}$ & -.14 & 249 \\
Slow Learner (SL) (IQ 75-90) & -.34 & 38 \\
$\begin{array}{l}\text { Learning Disabled and } \\
\text { Behaviorally Disordered/ } \\
\text { Emotionally Disturbed } \\
\text { (LD \& BD/ED) }\end{array}$ & & \\
\hline
\end{tabular}

than $61 \%$ of those placed in a regular class. Thus, unconditional judgments about mainstreaming must be tempered lest the special education field find itself in a morass similar to that created by the nature-nurture debate over intelligence.

Although this appears to be a significant finding, it raises the disturbing question of why some pupils placed in special classes are slightly worse off (in terms of achievement and social/personality adjustment) than they would have been had they been left in regular classrooms. The significant variable appears to be intelligence. If the child is placed in a special class because of a low IQ, it may lower teacher expectations for performance, which results in less effort on the teachers' part and less learning on the child's part (Smith, 1980). The lowered expectancy, be it conscious or unconscious, diverts instructional efforts away from academic pursuits toward a maintenance function.

On the other hand, the normal intelligence of LD and $\mathrm{BD} / \mathrm{ED}$ pupils (at least, by definition) apparently does not dampen teacher expectation. Teachers apparently take a more optimistic view and make a greater effort to improve academic functioning. Perhaps this effort represents the "real" special education - not a system seeking the status quo but a system focusing upon individual learning needs and abilities in order to design the most effective program of academic remediation necessary to overcome academic deficits.

These findings suggest that special education must become more than special methods and materials. If not combined with a shift toward more positive attitudes, its "specialness" is lost and no tangible benefits accrue to pupils. Since no particular service arrangement proved more effective, the differences appear to be related to indeterminate and imperceptible variables not easily assessed or controlled. Consequently, special education must seek not new technology but a frame of reference emphasizing the potential for growth in all its clientele. Such a posture will allow the "special" in special education to operate more effectively.

\section{Process Training}

The issue of process training is likely either to vex or to mollify practitioners in special education. Strong conviction exists on both sides, but the question remains: How efficacious is process training?

a. Psycholinguistic Training. Kavale (1981) performed a meta-analysis on 34 studies investigating its effectiveness. The studies yielded $240 \mathrm{ES}$ 's that produced an overall $\overline{\mathrm{ES}}$ of .39 . This finding was based on data representing approximately 1,850 subjects who averaged 7.5 years of age with a mean IQ of 82 and who received an average of 50 hours of psycholinguistic training. Thus, the average subject receiving psycholinguistic training stands at approximately the 65th percentile of subjects receiving no special psycholinguistic training, who remain at the 50 th percentile.

TABLE 2

Average Effect Sizes for ITPA Subtests

\begin{tabular}{lcc}
\multicolumn{1}{c}{ ITPA Subtest } & Mean Effect Size & $\begin{array}{r}\text { No. of } \\
\text { Effect } \\
\text { Sizes }\end{array}$ \\
\hline Auditory Reception & .21 & 20 \\
Visual Reception & .21 & 20 \\
Auditory Association & .44 & 24 \\
Visual Association & .39 & 21 \\
Verbal Expression & .63 & 24 \\
Manual Expression & .54 & 23 \\
Grammatic Closure & .30 & 21 \\
Visual Closure & .48 & 5 \\
Auditory Sequential Memory & .32 & 21 \\
Visual Sequential Memory & .27 & 21 \\
Auditory Closure & -.05 & 3 \\
Sound Blending & .38 & 3 \\
\hline
\end{tabular}

Table 2 presents ES's classified by ITPA subtest. These $\overline{\mathrm{ES}}$ 's are modest by most standards. If subtests for which the data are thin (i.e., 5 or fewer ES's) are eliminated, five of the nine subtests show small, albeit positive, effects. The case is different, however, for four abilities: auditory and visual association, verbal and manual expression. Thus, the average trained subject 
would be better off than approximately $65 \%$ to $73 \%$ of untrained subjects on associative or expressive abilities.

Subtests of the ITPA were patterned upon psycholinguistic constructs derived from Osgood's (1957) model of communication. Table 3 presents an analysis of the effects of training upon theoretical psycholinguistic dimensions underlying the ITPA. The box-score analysis

\section{TABLE 3}

\section{Average Effect Size for ITPA Psycholinguistic} Constructs

\begin{tabular}{llc} 
Dimension & \multicolumn{1}{c}{ Construct } & $\begin{array}{c}\text { Mean } \\
\text { Effect Size }\end{array}$ \\
\hline Level & Representational & .40 \\
Processes & Automatic & .21 \\
& Reception & .21 \\
& Organization & .32 \\
Modalities & Expression & .59 \\
& Auditory-Verbal & .32 \\
& Visual-Motor & .38 \\
\hline
\end{tabular}

offered by Hammill and Larsen (1974) suggested that both Representational Level and the Visual-Motor Modality were not particularly responsive to training. The $\overline{\mathrm{ES}}$ 's of .40 and .38 , respectively, for these abilities belie such an interpretation since the 15 and 14 percentile rank improvement shown by trained subjects in Representational Level and Visual-Motor Modalities subtests cannot be easily dismissed.

The ES data were next integrated for important study features, and the findings are shown in Table 4. Not surprisingly, prescriptive/individualized approaches were found superior to generalized/nonindividualized

TABLE 4

Average Effect Size for Study Features

\begin{tabular}{lcr} 
Feature & $\begin{array}{c}\text { Mean } \\
\text { Effect } \\
\text { Size }\end{array}$ & $\begin{array}{r}\text { No. of } \\
\text { Effect } \\
\text { Sizes }\end{array}$ \\
\hline $\begin{array}{l}\text { Approach } \\
\text { General }\end{array}$ & .37 & 38 \\
$\quad$ Prescriptive & .49 & 6 \\
Method & & \\
ITPA & .30 & 12 \\
PDLK & .49 & 14 \\
Other & .35 & 9 \\
\hline
\end{tabular}

methods. As with many other educational approaches, individualized instruction proved superior. The next finding was surprising; the Peabody Language Development Kits (PDLK) demonstrated the largest ES when compared to both ITPA-related activities and other methods (sensory, perceptual, or motor training activities).

On the surface, the superiority of the $P D L K$ appears contrary to expectation since ITP $A$-type activities should be most closely related to the criterion measure, the ITPA itself. Upon reflection, these findings are not surprising if viewed in terms of program structure. The $P D L K$ represents a highly structured sequence of lessons designed to increase general verbal ability, while ITPA training procedures (Bush \& Giles, 1977; Kirk \& Kirk, 1971) are only suggestions and guidelines for training activities. Consequently, they do not represent a comprehensive training package but merely examples for psycholinguistic training activities that must be structured and planned by individual teachers (Kavale, 1982a).

Although serving primarily a descriptive purpose, ES measurements can be subjected to a full range of statistical methods necessary to extract the most meaning from the data. One important technique is correlation to examine the association between the magnitudes of effect sizes and various study features as they range over many characteristics of the studies themselves. For example, the validity of experimental designs has been a primary battleground in the psycholinguistic training question. By using criteria established by Campbell and Stanley (1963), one can judge the internal validity of a study. Judgments about these criteria result in ratings of internal validity as either low, medium, or high, which are then correlated with the ES that study produced.

A primary question is whether the domain studied contains "good" and "bad" studies that reveal different findings. The resulting associations reveal whether relatively poorly designed studies give results significantly at variance with those of the best designed studies. If the quality of design (in the Campbell and Stanley sense) does correlate with ES, the "best" studies should be believed. In the case of no correlation between design quality and treatment effect (ES), no distinction between "good" and "bad" studies is necessary. This was found to be the case for the psycholinguistic training literature. When internal validity was correlated with $\underline{E S}$, a small positive correlation was found $(\underline{r}=+.22)$. The absence of an association suggests that there is no basis for discarding poor quality studies from the body of 
evidence and that indictment of the psycholinguistic training literature on the basis of design flaws is not warranted.

The findings regarding responsiveness to intervention of the Expressive constructs, particularly Verbal Expression, and the Representational Level subtests are most encouraging since they embody the "language" aspects of the ITPA and, ultimately, productive language behavior. For a basic area like language, the average elementary school pupil gains about one standard deviation $(\overline{\mathrm{ES}}=+1.00)$ over the school year and exceeds about $84 \%$ of the pupils' scores made on a language achievement measure at the beginning of the school year. The approximately $60 \%$ success rate for training Verbal Expression is thus substantial. In fact, roughly 50 hours of psycholinguistic training produce benefits on the Verbal Expression subtest $(\overline{\mathrm{ES}}=.63$ ), exceeding that which would be expected from one-half year of schooling in language achievement $(\overline{\mathrm{ES}}=.50)$.

A box-score analysis of the psycholinguistic training literature would have resulted in more equivocal conclusions since over half the reported outcomes were not statistically significant. Consequently, the selected benefits of psycholinguistic training must be considered. This is not an all-or-none proposition; caution must be exercised lest "the baby gets thrown out with the bath water," since specific situations exist where psycholinguistic training is effective and should be included within a total remedial program.

b. Perceptual-Motor Training. Perceptual-motor training represents a wide assortment of techniques aimed at improving abilities deemed necessary for both perceptualmotor functioning and academic achievement. Its popularity is based both on historical influences (since the days of Itard and Seguin) and the wide dissemination of clinical programs acknowledging the efficacy of perceptual-motor training.

Kavale and Mattson (in press) found 180 experiments assessing the efficacy of perceptual-motor training. A total of $637 \mathrm{ES}$ measurements was obtained, representing about 13,000 subjects who averaged 8 years of age with an average IQ of 89 and who received an average of 65 hours of perceptual-motor training. The $\overline{\mathrm{ES}}$ across 637 ES measurements was .802 which, in relative terms, indicates that a child who is no better off than average (i.e., at the 50th percentile) rises to the 53rd percentile as a result of perceptual-motor interventions. Additionally, of 637 ESs, $48 \%$ were negative, suggesting that the probability of obtaining a positive response to training is only slightly better than chance.
The overall effect of perceptual-motor training is thus negligible. Perhaps a single index may mask an important subset in which perceptual-motor training is more effective. Consequently, ES data were aggregated into increasingly differentiated groupings of outcome measures. The findings are shown in Tables 5 and 6 . These

TABLE 5

Average Effect Size

for Perceptual-Motor Outcome Classes

\begin{tabular}{lcc} 
Outcome Class & $\begin{array}{c}\text { Mean } \\
\text { Effect } \\
\text { Slze }\end{array}$ & $\begin{array}{r}\text { No. of } \\
\text { Effect } \\
\text { Sizes }\end{array}$ \\
\hline Perceptual/Sensory Motor & .166 & 233 \\
Academic Achievement & .013 & 283 \\
Cognitive/Aptitude & .028 & 95 \\
Adaptive Behavior & .267 & 26 \\
\hline
\end{tabular}

TABLE 6

Average Effect Sizes

for Perceptual-Motor General Outcome Categories

\begin{tabular}{lcr}
$\begin{array}{c}\text { General Outcome } \\
\text { Categorles }\end{array}$ & $\begin{array}{c}\text { Mean } \\
\text { Effect } \\
\text { Size }\end{array}$ & $\begin{array}{r}\text { No. of } \\
\text { Effect } \\
\text { Sizes }\end{array}$ \\
\hline $\begin{array}{l}\text { Perceptual/Sensory Motor } \\
\text { Gross motor }\end{array}$ & .214 & \\
$\quad \begin{array}{l}\text { Fine motor } \\
\text { Visual perception }\end{array}$ & .178 & 44 \\
$\quad$ Auditory perception & .149 & 28 \\
Academic Achlevement & .122 & 145 \\
$\quad$ Readiness & & 16 \\
Reading & .076 & 69 \\
Arithmetic & -.039 & 142 \\
Language & .095 & 26 \\
Spelling & .031 & 18 \\
$\quad$ Handwriting & .021 & 16 \\
Cognitive/Aptitude & .053 & 12 \\
$\quad$ Verbal IQ & & \\
Performance IQ & -.007 & 53 \\
\hline
\end{tabular}

findings speak for themselves. Regardless of how global or discrete the aggregation, the effects of perceptualmotor training present an unbroken vista of disappointment. There are no positive effects and nothing indicative of an effective intervention. 
Table 7 provides aggregated ES data for diagnostic category. The interpretation is clear: essentially zero

TABLE 7

Average Effect Size for Subject Groups

\begin{tabular}{lcc} 
Subject & $\begin{array}{c}\text { Mean } \\
\text { Effect } \\
\text { Size }\end{array}$ & $\begin{array}{r}\text { No. of } \\
\text { Effect } \\
\text { Sizes }\end{array}$ \\
\hline Normal & .054 & 58 \\
$\begin{array}{l}\text { Educable Mentally } \\
\quad \text { Retarded (IQ=50-75) }\end{array}$ & .132 & 143 \\
$\begin{array}{l}\text { Trainable Mentally } \\
\quad \text { Retarded (IQ=25-50) }\end{array}$ & .147 & 66 \\
Slow Learner (1Q=75-90) & .098 & \\
Culturally Disadvantaged & .045 & 14 \\
Learning Disabled & .018 & 85 \\
Reading Disabled & -.007 & 77 \\
Motor Disabled & .121 & 74 \\
\hline
\end{tabular}

effects are seen in all groups. In no instance were perceptual-motor interventions effective. In fact, among the lowest $\overline{\mathrm{ES}}$ s were those found for learning/reading disabled children for whom perceptual-motor training is a favored treatment approach.

Perceptual-motor training programs have taken a variety of forms, and the names associated with these programs read like the roster from the Special Education Hall of Fame. The $\overline{\mathrm{ES}}$ 's for the various training methods

TABLE 8

Average Effect Sizes for Perceptual-Motor Training Programs

\begin{tabular}{lcr} 
Training Program & $\begin{array}{c}\text { Mean } \\
\text { Effect } \\
\text { Slze }\end{array}$ & $\begin{array}{r}\text { No. of } \\
\text { Effect } \\
\text { Sizes }\end{array}$ \\
\hline Barsch & .157 & 18 \\
Cratty & .113 & 27 \\
Delacato & .161 & 79 \\
Frostig & .096 & 173 \\
Getman & .124 & 48 \\
Kephart & .064 & 132 \\
Combination & .057 & 78 \\
Other & -.021 & 82 \\
\hline
\end{tabular}

are shown in Table 8. Again, the findings offer a bleak picture. Nothing even hints at positive effects. The studies investigating the efficacy of individual programs included studies performed by both program advocates themselves and independent investigators. For example, the Delacato program, based upon the concept of neurological patterning, was assessed by both Delacato disciples and more critical investigators. The Delacato sources produced an $\overline{\mathrm{ES}}$ of .723 , and the non-Delacato sources revealed an $\overline{\mathrm{ES}}$ of -.242 . Thus, the possibility of vested interests in outcomes must be considered and may not appear in a selected review.

Ratings of internal validity revealed $83(46 \%)$ rated low, $62(35 \%)$ rated medium, and $35(19 \%)$ rated high. The largest ES was associated with low internal validity $(\overline{\mathrm{ES}}=.198)$, and the medium and high internal validity categories exhibited progressively smaller $\overline{\mathrm{ES}}$ 's of .042 and -.119 , respectively. On average, a trained subject in studies with adequate research design and control is worse off than $52 \%$ of control subjects receiving no perceptual-motor intervention.

Contrary to the suggestion that the available evidence does not allow either a positive or negative evaluation of perceptual-motor training (Hallahan \& Cruickshank, 1973), it appears not premature to draw negative conclusions regarding the efficacy of perceptual-motor interventions. Although the data from "poor" studies produced "large" effects in relation to findings from "good" studies, the integrated findings indicated that the combined treatment effects were practically zero. The addition of "poor" data with significantly larger treatment effects than found in "good" data did nothing to alter the bleak picture regarding the efficacy of perceptual-motor training.

Although engendering strong emotion, the question of process training defies unilateral interpretation. One form (psycholinguistic training) revealed selected positive benefits, while the other form (perceptual-motor training) failed to reveal any positive effects. Thus, one should be considered while the other should be dismissed as a feasible special education intervention.

\section{Medically-Based Interventions}

From its inception, special education has always shown a fascination for medicine. Conversely, at times, medicine has sometimes experienced a fascination with schools. The interface of this relationship has resulted in medicallyoriented interventions being an integral part of the special education repertoire of remedial techniques. 
a. Stimulant Drugs and Hyperactivity. The practice of treating hyperactive children with stimulant drugs is among the most controversial and emotionally loaded issues in special education. The medical community considers stimulant drugs to be the most efficacious treatment for hyperactivity. This conclusion has been challenged, first in the form of critical reviews suggesting that no positive interpretation could be drawn from extant literature because of numerous methodological flaws, and second in the form of ideological, political, and moral attacks upon stimulant drug treatment. Thus, empirical findings have proven less manifest than ethical positions, and the question of the efficacy of stimulant drug treatment remains.

Kavale (1982b) found 135 studies assessing the effectiveness of stimulant drug treatment for hyperactivity. The studies sampled represented approximately 5,300 subjects averaging 8.75 years of age with an average IQ of 102 who received medication for an average of 10 weeks. The $\overline{\mathrm{ES}}$ across 984 ES measurements was .578 , which suggests that an average drug-treated child would be expected to be better off than $72 \%$ of untreated control children.

The diverse assortment of outcomes measured in drug research makes it difficult to fully interpret a single index of drug efficacy. Three major outcome classes were identified (behavioral, cognitive, and physiological), and the findings are illustrated in Figure 2 in the form of normal distributions comparing hypothetical drugtreated and control populations. This more refined

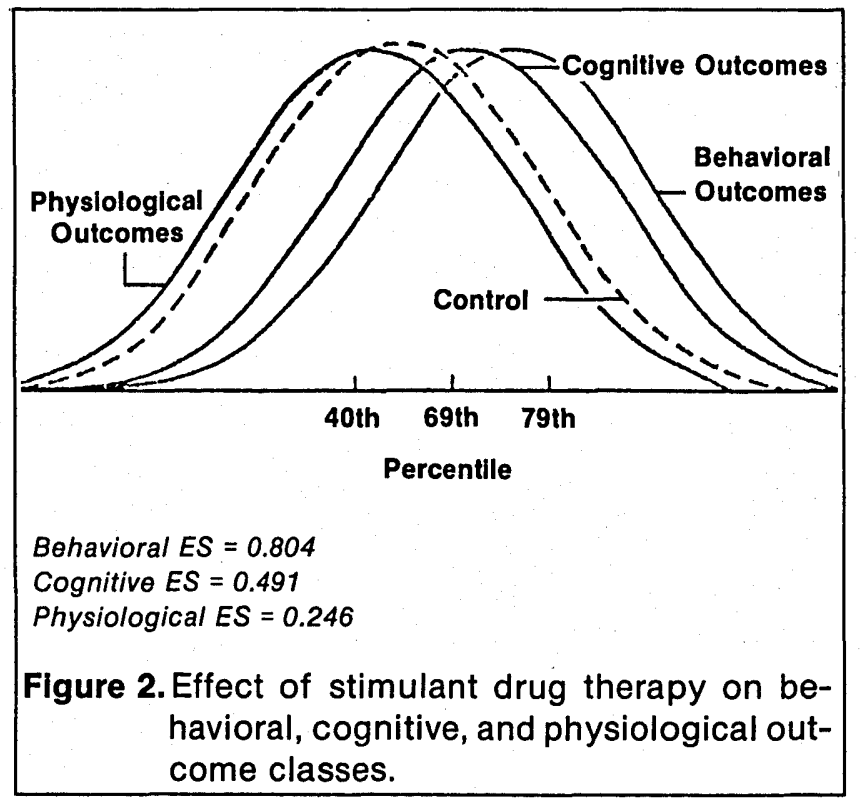

analysis revealed substantial positive effects on behavioral and cognitive outcomes. The negative effect for physiological outcomes indicated that drug intervention produced some negative consequences. (The physiological findings are generally difficult to interpret and are outside the scope of this article.)

Further refinement of the data in each outcome class is presented in Table 9. Note (with the exception of anxiety) the impressive gains on behavioral outcomes.

TABLE 9

Average Effect Sizes for Outcome Categories

\begin{tabular}{lcc} 
& $\begin{array}{c}\text { Mean } \\
\text { Effect } \\
\text { Size }\end{array}$ & $\begin{array}{r}\text { No. of } \\
\text { Effect } \\
\text { Sizes }\end{array}$ \\
\hline $\begin{array}{l}\text { Behavioral } \\
\quad \text { Global Improvement }\end{array}$ & .886 & 192 \\
$\quad$ Ratings & .837 & 113 \\
Rating Scales \& Checklists & .846 & 127 \\
Activity Level & .782 & 119 \\
$\quad$ Attention \& Concentration & & \\
Behavior (Social \& & .634 & 92 \\
$\quad$ Classroom) & .118 & 12 \\
$\quad$ Anxiety & & \\
Cognitive & .391 & 54 \\
Intelligence & .383 & 47 \\
$\quad$ Achievement & .467 & 38 \\
$\quad$ Drawing \& Copying & & \\
Perceptual, Memory, \& & .412 & 91 \\
$\quad$ Motor & .367 & 41 \\
$\quad$ Learning Characteristics & & \\
Physiological & .558 & 7 \\
$\quad$ Biochemical & -.275 & 51 \\
\hline Psychophysiological & & \\
\hline
\end{tabular}

Substantial benefits were found in ratings of behavioral functioning, lowered activity levels, and improved attending skills. Although not of the same magnitude as behavioral improvements, cognitive functioning also exhibited improvement.

The overall $\overline{\mathrm{ES}}$ of .578 for stimulant drugs was obtained from six major drugs as shown in Table 10. All major drugs with the exception of caffeine appear to be effective in the treatment of hyperactivity. These findings provide support for stimulants being the most popular treatment for hyperactivity. 
TABLE 10

Average Effect Sizes for Stimulant Drugs

\begin{tabular}{lcc}
\multicolumn{1}{c}{ Drug } & $\begin{array}{c}\text { Mean } \\
\text { Effect } \\
\text { Size }\end{array}$ & $\begin{array}{c}\text { No. of } \\
\text { Effect } \\
\text { Sizes }\end{array}$ \\
\hline Methylphenidate (Ritalin) & .634 & 540 \\
Dextroamphetamine (Dexedrine) & .585 & 276 \\
Magnesium Pemoline (Cylert) & .540 & 61 \\
Levoamphetamine & .447 & 29 \\
Amphetamine (Benzedrine) & .438 & 33 \\
Caffeine & .111 & 45 \\
\hline
\end{tabular}

The literature on drugs has been criticized on methodological grounds, but no significant differences were

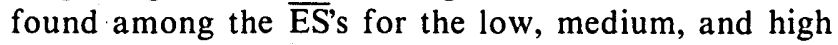
categories of internal validity ratings. Design problems thus appeared to play a subordinate role in drug research.

Stimulant drug treatment appears to be an effective intervention for the treatment of hyperactivity. Compare this conclusion with this statement from a narrative review of the drug literature: "Our analysis of the literature in this area indicates that research findings do not indicate the general efficacy and therefore do not support the widespread use of stimulant drugs. .." (Adelman \& Compas, 1977, p. 406). Could these diametrically opposed conclusions be based upon the same data base? Obviously, they can, and the reasons for the contradiction are found in the methodology. Meta-analysis is objective, precise, and empirical compared to the subjective, general, and conjectural nature of narrative integrations. Narrative reviews may undermine confidence in a field since their failure to find reliable conclusions is viewed as the true state of affairs when, in fact, it is the result of not perusing the research review with sufficient ingenuity to uncover what has been found.

No empirical analysis can hope to elucidate the complex ideological and ethical questions associated with stimulant drug treatment for hyperactivity. Although the drug literature presents a complex amalgam of findings, the beneficial effects of stimulant drugs for treating hyperactivity have been demonstrated.

b. Diet Treatment of Hyperactivity. Dr. Benjamin Feingold offered the hypothesis that ingestion of artificial (synthetic) food additives (colors and flavors) results in hyperactivity in children (Feingold, 1976). The suggested treatment was based upon the Feingold Kaiser-Permanente (K-P) diet designed to eliminate from the diet all foods containing artificial food additives (Feingold \& Feingold, 1979). Empirical support has been equivocal and raises the question: Are the major dietary changes required by the Feingold K-P diet justified in terms of reduced hyperactivity?

Kavale and Forness (in press) examined 23 studies assessing the efficacy of the Feingold K-P diet in treating hyperactivity. The 23 studies produces $125 \mathrm{ES}$ measurements and yielded an $\overline{\mathrm{ES}}$ of .118. The average subject was 8.3 years of age, had an IQ of 99 , and remained on the Feingold K-P diet for 39 weeks. In relative terms, the $.118 \mathrm{ES}$ indicates that a child no better off than average (i.e., at the 50th percentile) would rise to the 55th percentile as a result of the Feingold K-P diet. When compared to the 22 percentile ranks gain for stimulant drug treatment, the 5 percentile rank improvement for diet intervention is less than one-fourth as large. Although the average ages and IQs were similar for drugtreated and diet-treated subjects, the average duration of treatment differed: 39 versus 10 weeks. In relation to $\overline{\mathrm{ES}}$ (.118 vs. .587), these comparisons suggest that drug treatment is approximately five times as effective in about one-fourth the time when compared to Feingold $\mathrm{K}-\mathrm{P}$ diet treatment.

The ES data were next aggregated into descriptive outcome categories. The findings are shown in Table 11.

TABLE 11

Average Effect Size for Outcome Categories

\begin{tabular}{lcr} 
Category & $\begin{array}{c}\text { Mean } \\
\text { Effect } \\
\text { Size }\end{array}$ & $\begin{array}{r}\text { No. of } \\
\text { Effect } \\
\text { Sizes }\end{array}$ \\
\hline Conners Scale - Parents & .156 & 26 \\
Conners Scale - Teachers & .268 & 9 \\
Global Improvement & .128 & 23 \\
Hyperkinesis Rating & .293 & 15 \\
Attention & .015 & 36 \\
Disruptive Behavior & .052 & 6 \\
Impulsivity & .153 & 5 \\
Learning Ability & -.055 & 10 \\
\hline
\end{tabular}

The only obvious effect of diet treatment is upon overt behavior - specifically, a reduction in hyperactivity with little influence upon more cognitive aspects of 
behavior. This conclusion, however, must be tempered. Global ratings of improvement possess two major problems: objectively defining improvement, and psychometric deficiencies (reliability and validity). These problems influence the "reactivity" or subjectivity of outcome measures. The correlation of ES and ratings of reactivity was significant $(r=.181)$, suggesting that larger treatment effects were slightly associated with more reactive measures. Additionally, aggregations of reactive versus nonreactive measures found $\overline{E S}$ 's of .179 and .001 , respectively, suggesting that in instances in which instruments paralleled the valued outcomes of observers, there was a tendency to view more improvement as revealed in larger treatment effects.

Of the 23 studies, six were uncontrolled clinical trials that yielded an $\overline{\mathrm{ES}}$ of .337 compared to the $\overline{\mathrm{ES}}$ of .089 for the 17 controlled studies. There was, however, a significant relationship ( $\underline{r}-.193)$ between ES and ratings of design quality. Larger ES's were associated with studies rated low on internal validity, which makes it difficult to attribute improvement to the treatment rather than to artifacts of the study conditions.

The controlled studies used two primary experimental designs. The diet crossover studies $(\mathrm{N}=7)$ exhibited an $\overline{\mathrm{ES}}$ of .196 , while challenge studies $(\mathrm{N}=10)$ revealed an $\overline{\mathrm{ES}}$ of .045 . Diet crossover studies (ones in which the control group is placed on a disguised Feingold K-P diet), though an improvement over uncontrolled clinical studies, still possess methodological difficulties. Challenge studies (ones in which the experimental group is "challenged" with a food containing eliminated substances) offer a methodology that permits attribution of behavioral change to the substances eliminated in the Feingold K-P diet. Challenge studies can thus be considered the "best" studies, but the weight of this evidence is decidedly negative $(\overline{\mathrm{ES}}=.045)$.

Although the Feingold diet offers an appealing treatment approach for hyperactivity, the available evidence suggests that the Feingold K-P diet is not an effective intervention for hyperactive children. Yet, as was the case with perceptual-motor training, the widely publicized clinical evidence and quasi-religious belief espoused by "Feingold Associations" will make it difficult to depose diet intervention as a treatment alternative for hyperactivity.

Thus, the fascination with medical interventions by special education is not entirely warranted. The findings related to medically based interventions suggest that medicine does not necessarily offer "better" treatments than those based upon psychoeducational foundations.
Therefore, special education should not be enamored of medical interventions. They require the same critical examination as techniques emanating from any other discipline.

\section{META-ANALYSIS CONCLUSIONS FOR SPECIAL EDUCATION}

The findings from meta-analysis are not used either to confirm or to reject hypotheses but, rather, to establish facts - dependable relationships that regularly occur despite any biases that may be present because of particular procedures used in a study. These facts may then be used to influence policy, practice, or theory in special education. The facts from meta-analysis are not loosely constructed, because they meet the standards of objectivity, verifiability, replicability, and clarity found in primary empirical research.

The findings from meta-analysis are subject to questions of external validity, or the extent to which findings can be generalized to a population of interest in "real" situations. There is no simple answer. The special education practitioner must share in determining external validity by studying the context in which the findings were obtained. If the contexts of the research setting and applied setting are judged to be sufficiently similar, the research findings will possess greater applicability in the "real" situation.

External validity is not, however, the final mediator of treatment effectiveness. A wide variety of intervening variables carries the special education teachers' influence from the business of teaching to the exceptional child's business of learning. These intervening variables are the elements that either impart or detract from the "special" in special education. One significant constituent surrounds expectations - that which special education practitioners expect of children and for which they are held responsible. In an ethnographic study of a special education classroom, George (1981) provided insight into the important and significant role of expectation on the part of the teacher.

It is perhaps unfortunate that the whole concatenation of intervening variables have little to do with the treatment programs and techniques falling under the rubric of special education. They represent privately held motives on the part of special education teachers that define the contingencies of the relationship between special education teachers and pupils. Thus, regardless of how "special" the intervention, the key factor surrounds the 
teacher and a series of ill-defined affective variables exerting a profound effect upon performance.

A special education teacher's success has little to do with models of teaching and learning. In fact, these educational models (i.e., programs of what to teach, when, how, and the like), if successful, reveal success to be enormously variable (House, Glass, McLean \& Walker, 1978). A simple truism emerges: What works in one place often does not work someplace else. The variability of treatment effectiveness (expressed as the standard deviation of $\overline{E S}$ ) is typically greater than the average effectiveness of the treatment. Consider the treatments reviewed here: regular class placement $(\overline{\mathrm{ES}}=$ $-.12 ; \mathrm{SD}=.65)$, psycholinguistic training $(\overline{\mathrm{ES}}=.39, \mathrm{SD}=$ $.54)$, perceptual-motor training $(\overline{\mathrm{ES}}=.082 ; \mathrm{SD}=.269)$, stimulant drug treatment $(\overline{\mathrm{ES}}=.578 ; \mathrm{SD}=.608)$, and diet treatment $(\overline{\mathrm{ES}}=.118 ; \mathrm{SD}=.415)$. In each case, the treatment exhibited great variability in relation to efficacy. On average, the effect size was consistently onehalf as large as the standard deviation of effect sizes. Thus, special education treatments are more variable in their effects than they are, on the average, beneficial in their effects.

This variability produces yet another problem: Special education interventions may produce benefits, but in a manner that is essentially unpredictable. If some feature(s) of studies (e.g., age, sex, IQ, SES, or the like) could be discovered that were to correlate with ES, one would be able to predict that some intervention will be effective here but not there, and so on. Unfortunately, in no area of special education are the correlations of a magnitude that permits useful predictions.

Whether or not special education intervention makes a difference is contingent upon an intricate and bewildering set of interacting constituents that defy a simple response to the question: Is special education special? At best, meta-analysis offers only a conditional rendering of issues in special education. This limitation would cast doubt upon any suggestion for prescriptive policy - that is, a single course of action under a wide range of circumstances. Special education simply can not be reduced to a simple set of input-output relationships (e.g., do $\mathrm{A}$ in circumstances $\mathrm{X}$ and $\mathrm{Y}$, and do $\mathrm{B}$ in circumstance $Z$ ).

Therefore, special education may have to be treated as an enterprise that is unlawful, unpredictable, and unknowable in the traditional scientific sense. Operating under uncertainty is possible, but it requires that teachers be versatile and flexible rather than dogmatic (Glass, 1979). Research operates in a theoretical world in which findings do not automatically apply in the real world. Phillips (1980) termed this the is/ought dichotomy: Research findings take an is form (i.e., $\mathrm{X}$ is $\mathrm{Y}$ ) while practical implications take an ought form (i.e., A ought to do $\mathrm{B}$ to $\mathrm{C}$ ). But there is no necessary ought conclusion from an is; the transformation requires a value judgment. These judgments involve the practitioner and the myriad interviewing variables that interpose between theory and practice.

\section{META-ANALYSIS AND SPECIAL EDUCATION: AN ASSESSMENT}

Although the success or failure of special education is contingent upon relatively uncontrolled (and unknown) factors, practitioners must operate from a rational basis. This can be accomplished only if the research literature is approached with the same attitude of data analysis as is applied to the quantitative summaries of individual studies to produce more rigorous and objective conclusions (Cooper \& Rosenthal, 1980).

Meta-analysis as a technique of empirical data synthesis offers three specific benefits: obtaining an estimate of the magnitude of experimental effects, greater insight into the form of relationships among variables, and the ability to examine contradictions in a group of studies (Pillemer \& Light, 1980). These benefits allow metaanalysis to expose many putative "truths" in special education as "myths" and to counter many established generalizations. But, as we suggested earlier, "Metaanalysis is a process of condensation that shows what is known in an area like special education - but also what is not known. It provides a summation - but not an end. In this sense, meta-analysis represents only a beginning" (Kavale \& Glass, 1981, p. 538).

\section{REFERENCES}

Adelman, H. S., \& Compas, B. E. Stimulant drugs and learning problems. Journal of Special Education, 1977, 11, 377-416.

Blatt B., \& Garfunkel, F. Teaching the mentally retarded. In R. Travers (Ed.), Second handbook of research on teaching. Chicago: Rand McNally, 1973.

Bush, W. J., \& Giles, M. T. Aids to psycholinguistic teaching (2nd ed.). Columbus, OH: Charles E. Merrill, 1977.

Campbell, D. T., \& Stanley, J. C. Experimental and quasi-experimental designs for research. Chicago: Rand McNally, 1963.

Carlberg, C. \& Kavale, K. The efficacy of special versus regular class placement for exceptional children: A meta-analysis. Journal of Special Education, 1980, 14, 295-309.

Cooper, H., \& Rosenthal, R. Statistical versus traditional procedures for summarizing research findings. Psychological Bulletin, 1980, $87,442-449$. 
Cruickshank, W. M. When winter comes, can spring ...? Exceptional Child, 1978, 25, 3-25.

Dunn, L. M. Special education for the mildly retarded - Is much of it justifiable? Exceptional Children, 1968, 35, 5-22.

Feingold, B. F. Hyperkinesis and learning disabilities linked to the ingestion of artificial food colors and flavors. Journal of Learning Disabilities, 1976, 9, 551-559.

Feingold, B. F., \& Feingold, H. S. The Feingold cookbook for hyperactive children. New York: Random House, 1979.

George, C. A. Room 22: Ms. Russell's class. Boulder, CO: Laboratory of Educational Research, University of Colorado, 1981.

Glass, G. V, Primary, secondary, and meta-analysis of research. Educational Researcher, 1976, 5, 3-8.

Glass, G. V. Integrating findings: The meta-analysis of research. In L. Shulman (Ed.), Review of Research in Education, 1977, 5, 351-379.

Glass, G. V. Policy for the unpredictable (uncertainty research and policy). Educational Researcher, 1979, 8, 12-14.

Glass, G. V , McGaw, B., \& Smith, M. L. Meta-analysis in social research. Beverly Hills, CA: Sage, 1981.

Glass, G. V , \& Smith, M. L. Meta-analysis of research on class size and achievement. Educational Evaluation \& Policy Analysis, 1979, 1, 2-16.

Guskin, S. L., \& Spicker, H. H. Educcational research in mental retardation. In N. R. Ellis (Ed.), International review of research in mental retardation (Vol. 3). New York: Academic Press, 1968.

Hallahan, D. P., \& Cruickshank, W. M. Psychoeducational foundations of learning disabilities. Englewood Cliffs, NJ: Prentice-Hall, 1973.

Hammill, D. D., \& Larsen, S. C. The effectiveness of psycholinguistic training. Exceptional Children, 1974, 41, 5-14.

Hedges, L. V., \& Olkin, I. Vote-counting methods in research synthesis. Psychological Bulletin, 1980, 88, 359-369.

House, E. R., Glass, G. V , McLean, L. D., \& Walker, D. F. No simple answer. Critique of the Follow Through evaluation. Harvard Educational Review, 1978, 48, 128-160.

Jackson, G. B. Methods for integrative reviews. Review of Educational Research, 1980, 50, 438-460.

Johnson, G. O. Special education for the mentally handicapped - A paradox. Exceptional Children, 1962, 29, 62-69.

Kavale, K. Functions of the Illinois Test of Psycholinguistic Abilities (ITPA): Are they trainable? Exceptional Children, 1981, 47, 496-510.

Kavale, K. Psycholinguistic training programs; Are there differential treatment effects? Exceptional Child, 1982, 29, 21-30. (a)

Kavale, K. The efficacy of stimulant drug treatment for hyperactivity: A meta-analysis. Journal of Learning Disabilities, 1982, 15, 280289. (b)

Kavale, K. A., \& Forness, S. R. Hyperactivity and diet treatment: A meta-analysis of the Feingold hypothesis. Journal of Learning Disabilities, in press.

Kavale, K. A., \& Glass, G. V. Meta-analysis and the integration of research in special education. Journal of Learning Disabilities, 1981, 14, 531-538.

Kavale, K. \& Mattson, P. D. "One jumped off the balance beam": Meta-analysis of perceptual-motor training. Journal of Learning Disabilities, in press.

Kirk, S. A. Research in education. In H. A. Stevens \& R. Heber (Eds.), Mental retardation: A review of research. Chicago: University of Chicago Press, 1964.

Kirk, S. A., \& Kirk, W. D. Psycholinguistic learning disabilities: Diagnosis and remediation. Urbana: University of Illinois Press, 1971.

Light, R. J. Capitalizing on variation: How conflicting research findings can be helpful for policy. Educational Researcher, 1979, 8, 7-11.
Light, R. J., \& Smith, P. V. Accumulating evidence: Procedures for resolving contradictions among different research studies. Harvard Educational Review, 1971, 41, 429-471.

Lund, K. A., Foster, G. E., \& McCall-Perez, F. C. The effectiveness of psycholinguistic training: A reevaluation. Exceptional Children, 1978, 44, 310-319.

MacMillan, D. L. Special education for the mildly retarded: Servant or savant. Focus on Exceptional Children, 1971, 2(9), 1-11.

Miller, T. I. Drug therapy for psychological disorders. In H. J. Walberg \& E. H. Haertel (Eds.), Evaluation in education: An international review series, 1980, 4, 96-97.

Milofsky, P. D. Why special education isn't special. Harvard Educational Review, 197.4, 44, 437-458.

Minsk off, E. Research on psycholinguistic training: Critique and guidelines. Exceptional Children, 1975, 42, 136-144.

Newcomer, P., Larsen, S. \& Hammill, D. A response. Exceptional Children, 1975, 42, 144-148.

Osgood, C. E. Motivational dynamics of language behavior. In M. R. Jones (Ed.), Nebraska symposium on motivation. Lincoln: University of Nebraska Press, 1957.

Peterson, P. L. Open versus traditional classrooms. In H. J. Walberg \& E. H. Haertel (Eds.), Evaluation in education: An international review series, 1980, 4, 58-60.

Phillips, D. C. What do the researcher and the practitioner have to offer each other? Educational Researcher, 1980, 9, 17-20, 24.

Pillemer, D. B., \& Light, R. J. Synthesizing outcomes: How to use research evidence from many studies. Harvard Educational Review, 1980, 50, 176-195.

Rosenthal, R. The "file drawer problem" and tolerance for null results. Psychological Bulletin, 1979, 86, 638-641.

Shattuck, M. Segregation versus non-segregation of exceptional children. Journal of Exceptional Children, 1946, 12, 235-240.

Smith, M. L. Teacher expectation. Evaluation in Education: An International Review Series, 1980, 4, 53-55.

Smith, M. L. \& Glass, G. V. Meta-analysis of psychotherapy outcome studies. American Psychologist, 1977, 32, 752-760.

Smith, M. L. \& Glass, G. V. Meta-analysis of research on class size and its relationship to attitudes and instruction. American Educational Research Journal, 1980, 17, 419-433.

\section{Beverly Dexter \\ Lynchburg College}

As a high school resource room teacher for learning disabled students, $I$ often find that although the students may be capable of doing the academic work required for college, very few of them even consider pursuing a postsecondary degree. They seem to be overwhelmed at the idea of being able to prepare for a career that requires more schooling. As a result, even my more capable students resign themselves to becoming semi-skilled laborers 
in the job force. How can I convince them otherwise? And once I do, how do I prepare them for the academic requirements of either a two-year or a four-year college program?

Convincing a learning disabled adolescent that a career in business, economics, or teaching may be possible is often like convincing the average human being that at the end of a rainbow is indeed a pot of gold. Both concepts meet with disbelief in most instances. Nevertheless, the career, like the pot of gold and the proverbial definition of beauty, is in the eye of the beholder. Belief must come from within, with possible external encouragement. The key to success in convincing a person of the true value of his or her abilities lies in self-concept beliefs.

Therefore, the first step would be to help develop a positive feeling of self worth within the individual. In the case of the learning disabled adolescent, comparisons between former level of achievement and current successes should be explored openly. Discussions of the strengths and weaknesses the student now possesses must be done realistically.

Most colleges and universities do expect a fairly high degree of independence from their students, and individual learning needs are frequently ignored in the average college classroom. If a student has become too dependent on a high school resource teacher for additional help in all the academic endeavors, he or she will be at a disadvantage when encountering a college campus where special resources are not readily a vailable. Thus, instruction should be geared toward helping the student become more independent in learning activities if the student is even contemplating going on to a two-or four-year college following graduation from high school. Learning to be independent may be more difficult for LD students than any of the subject matter content they may experience at college. A great deal of intestinal fortitude is needed to step forward and admit a learning disability in a setting where the "cream of the crop" is expected to be the norm.

A first step would be to explore the possible colleges and universities that meet both the student's career and learning needs. A list of colleges and universities that provide services for learning disabled students is published by the Association for Children with Learning Disabilities (4156 Library Rd., Pittsburgh, PA 15234).
Similar publications are available through Academic Therapy, 20 Commercial Blvd., Novato, CA 94947, and ERIC, 1920 Association Drive, Reston, VA 22091.

After generating a list of possible schools, the student should investigate entrance requirements for each one. When standardized tests, such as the SATs, are required, the student should request that these be taken orally if necessary. If the college administers its own tests, the student should request further information concerning adjusted administration procedures that may be needed to allow best performance.

In the meantime, the resource teacher should be working closely with the student on developing appropriate study skills for independent learning at the college level. Ideally, such work should begin early in high school and continue through graduation. An initial activity related to study skills deals with organization - of time, materials, and assignments. The student should establish a set time for studying when a way from the school atmosphere. He or she probably realizes by now that studying may require three times the amount of clock hours put in by peers, and should thus learn to budget his or her time accordingly. As time progresses, the student should be able to estimate the amount of time necessary for each assignment and to schedule this amount of time.

Organizing the necessary materials when preparing to study may be half the battle for many students - not just those with learning disabilities! Only the materials needed for an assigned task should be in the student's view, and reference materials should be within easy reach. Clutter should be kept at a minimum, and all other distractors should be avoided if possible. Students who become easily distracted by auditory stimuli could use ear plugs (Fleets ${ }^{\circledR}$ puts out especially good ones) or head phones with the music turned off. Visual distractors should also be manipulated within the environment.

Few students have learned how to study, despite their arguments to the contrary ("I spent five hours studying for the quiz, but I didn't remember a thing once I got in there to take it!"). In reality, most students consider reading over an assignment the same thing as studying it. The truth of the matter is that reading an assignment over and over can result in two outcomes: rote memorization of facts with no thinking or conceptualizing involved, or total boredom from repetition and little or no retention of the "studied" information. 
Unfortunately, answers regarding teaching or learning how to study are not easy to come by. A great deal depends on the student's individual learning style and how well he or she is able to utilize memory. Another important factor is the type of test or evaluation procedure utilized in checking the student's knowledge and understanding of the subject matter. If the student knows that he or she will be taking a test in the "truefalse" format, he or she should be prepared to identify facts that can best be learned through rote memory. If an essay format is to be used, the student should practice putting concepts and facts together in written form. Far too many tests stress only factual material and, thus, students become conditioned to learn only rote facts. At more advanced levels, however, the emphasis tends to change to a higher level of cognitive thinking that requires synthesis as well as analysis of the material content. Students should be made aware of this, and should be given opportunities to practice putting their ideas into words, either on paper or on tape.

Aside from the above-mentioned activities, which focus on academics, the student should learn how to discuss his or her learning disability with teachers. Most college or university professors really do want their students to learn and to be successful in their attempts at learning. Unless they are made a ware of the individual student's needs, however, they may misinterpret the reason behind an apparent lack of learning. This does not mean that the learning disability should be misused as a crutch. Rather, it means that the student can benefit by learning to discuss his or her disability in an objective manner.

Role playing situations can be helpful in learning how to discuss one's self with one's "superiors." Variations on the role plays can add several dimensions to the original activity. Initially, positive and compassionate listeners should be incorporated into the role plays. Later, more negative aspects might be added to help desensitize the student. Although this sounds cruel, in the long run such activities will help the student in a variety of "real world" situations he or she may face after graduating from high school. The idea is to help students learn to be more self confident while dealing with their own weaknesses. Therefore, their strengths should be identified and incorporated into the total learning process.

In summary, convincing students who have been in a resource or special program most of their lives that they are capable of continuing their education past the secondary level may not be easy. Further, once they become convinced, they need to be totally prepared for the independent learning activities that will be expected of them at the postsecondary level. Learning appropriate study skills is basic to success in the academic world of the college or university, and practice of these skills should begin early in the student's high school years - or even before then, if possible, since most learning disabled students must focus on learning how to learn before they can even consider what they are to learn. Lastly, role playing activities may be used to help the student practice for future encounters with college instructors who may or may not fully understand the implications of having a learning disability at the college level.

\section{ALERT}

February 16-19, 1983

Association for Children and Adults With

Learning Disabilities

Washington Hilton Hotel

Washington, DC

March 10-12, 1983

Microcomputers in Special Education

Hartford, Connecticut

Contact: Council for Exceptional Children, 1920 Association Dr., Reston, VA 22091

April 4-8, 1983

Council for Exceptional Children

Cobo Hall

Detroit, MI 